\title{
Adolescent/Youth Utilization of Reproductive Health Services: Knowledge Still a Barrier
}

\author{
Saratu O. Ajike, Valerie C. Mbegbu \\ Department of Public Health, School of Public \& Allied Health, Babcock University, Ilisan-Remo, Nigeria \\ Email address: \\ Suo2009@gmail.com (S. O. Ajike), valeriembegbu@yahoo.com (V. C. Mbegbu)
}

\section{To cite this article:}

Saratu O. Ajike, Valerie C. Mbegbu. Adolescent/Youth Utilization of Reproductive Health Services: Knowledge Still a Barrier. Journal of Family Medicine and Health Care. Vol. 2, No. 3, 2016, pp. 17-22. doi: 10.11648/j.jfmhc.20160203.12

Received: September 4, 2016; Accepted: October 14, 2016; Published: October 21, 2016

\begin{abstract}
As a country drives efforts in establishing adolescent/youth friendly services to cater to the unique reproductive and sexual health of adolescents/youths, it is pertinent that the youth know about these services to be able to access and benefit from them. This study therefore examined the knowledge of youths on available adolescent/youth friendly services (A/YFRHS) in Ikeja, Lagos State, Nigeria. The study was a descriptive cross-sectional survey that collected data from 427 (15 to 24) year olds. Respondents answered questions on general knowledge of A/YFRHS, Sources of knowledge about A/YFRHS, Services offered by A/YFRHS facilities and identification of locally available A/YFRHS. Data were analyzed using SPSS version 21 to generate descriptive statistics. Two hundred and twenty-eight (82\%) of the respondents had general knowledge about A/YFRHS. More than half, 268 (79.5\%) of the respondents did not know of a specific A/YFRHS provided in study area. Friends/peers (45.7\%) were the best source of information on A/YFRHS. The most popular services known were family planning $(81.6 \%)$, voluntary counselling and testing $(73.8 \%)$, and sexually transmitted diseases $(67.3 \%)$. Knowledge was low $(\mathrm{SE}=0.11 ; \mathrm{SD}=2.20)$ with a mean score of 5.46 on a 10 -point scale. The participants knew what adolescent/youth friendly services were but did not know where to get these services from because they were not aware of the available A/YFRHS facilities. Extensive awareness of locally available A/YFRHS is needed in the study area.
\end{abstract}

Keywords: Adolescents Services, Developing Countries, Reproductive Health, Youth, Youth Friendly Services

\section{Introduction}

Youths 35 years and under in Nigeria make up about $70 \%$ of the population [1]. These youths due to their rapid development are vulnerable to a lot of health risks and most of these risks are related to their sexual and reproductive health [2]. The reproductive health ( $\mathrm{RH})$ services in the family health program are traditionally targeted at married couples [3] but some are now accessed by youths in some health facilities. Currently, youth friendly services are developing in Nigeria. In a recent assessment of youth friendly services in Nigeria, $59 \%$ of the available youth friendly services facilities offered integrated services while $37 \%$ offered youth only services [4]. Despite growth of youth friendly services it has been reported that utilization of available health services is recorded to be lowest amongst youths [5].

Initially, youths were thought of to be healthy and not in need of special health services [6]. As a result, youth's unique health needs, behaviours, expectations and routine health care services are not well geared to provide the needed services [7]. Now, there is a better understanding of this age group as regards sexual and reproductive health behaviour and the need to for them to utilize services specially catering to their need.

\section{The Need for Adolescents and Youths to Access A/YFRHS}

As youths form a sizable number in the country, they have a need for well oriented reproductive health service that should be provided by efficient and skilled health workers [7]. Furthermore, young people experience a lot of sexual and reproductive health problems [8] such as physiological vulnerability, high susceptibility to peer pressure, tendency to engage in risk-taking behaviour, less ability to negotiate safer sex practices, and difficulty accessing reproductive health 
information and services [9] and as such require youth friendly services to meet their needs. Literatures have indicated that sexual health education which can be provided by youth friendly reproductive health services for adolescents and youths rather promotes safer sex and at the same time does not encourage them to increase sexual activities contrary to earlier misconceptions [9].

Youths and adolescents who are often reluctant to discuss sensitive health issues can benefit from youth friendly health services [10]. Issues of poor disclosure are better handled when youths/adolescents can access youth friendly services [11]. Further studies pointed out the ability of youth friendly services to effectively attract youths, meet their needs comfortably and responsively, and succeed in retaining the young clients for continuing care [12]. When young people have access to health and education, which can be obtained in A/YFRHS, they become a powerful force for economic development and positive change [13]. When adolescents and youths are properly counselled and educated, there will be an improvement in their sexual and reproductive health knowledge and this would encourage them to adopt safer sexual behaviours that will in turn safeguard the health of future generations [14].

Despite noted benefits, the access to and utilization of youth friendly sexual and reproductive health services remains a primary concern of the promotion of sexual and reproductive health and rights [15] as youths are faced by a lot of challenges related to the sensitive nature of adolescent sex and sexuality [16].

In Nigeria, the realization of the magnitude of reproductive health problems the youth face prompted the government to make it an issue of national health priority [15]. Unfortunately, availability of A/YFRHS remains poor in Nigeria. Non-governmental organizations have been in the forefront of providing A/YFRHS, but their reach is low and their number as well as spatial distribution cannot guarantee equitable access to young people across the country [16]. However in recent times there have been some efforts to establish A/YFRHS in some states.

\section{How Knowledge Affects Utilization of A/YFRHS}

Although there are upcoming youth friendly services, most youths are not aware of these services. Several studies have noted the influence of knowledge or lack of it on health services utilization $(3,12,17$, and 18]. So, without the knowledge of available services, there would be poor utilization of these services. On the other hand, knowledge is important in increasing the utilization of the available youth friendly services, which could result in optimal utilization of the available services [17]. A considerable population of young people, are sexually-active and increasingly engage in risky sexual behaviours [19]. Further studies suggest that many sexually-active young people do not use contraception or seek treatment for sexually transmitted infections because of lack of knowledge about places for getting methods or the infection treatment, lack of awareness of the infections themselves or because of perceived barriers in accessing health services [20]. This continues to place them at risk of diminished sexual and reproductive health. Another study [21] noted that the level of the adolescent's knowledge on the type of sexual and reproductive health services provided, health service providers and, their attitude towards health services are main determinants of access and use of health services. Moreover, the primary reason for inadequate understanding of youths on sexual and reproductive health was due to the absence of awareness of youth friendly services [18].

Youths' confidence in appropriately addressing reproductive health problems has also been associated with poor knowledge. In a study by [3] participant's lack of confidence in solving reproductive and sexual health related problems was linked to unawareness of reproductive and sexual health which they could have had access to at the A/YFRHS facilities. They were unanimous in suggesting that increased awareness about adolescent and youth health services would promote better utilization of services. Therefore this study sought to examine the level of knowledge of youths in the study area about available A/YFRHS.

\section{Materials and Methods}

\subsection{Study Design and Sample Size Determination}

The study was a cross sectional study among 427 adolescents and youths selected from a total of 139, 391 [22] in Ikeja local government of Lagos State. The sample size was determined using $\mathrm{n}=\mathrm{z}^{2} \mathrm{pq} / \mathrm{d}^{2}$, where $\mathrm{n}=$ The desired sample size; $\mathrm{z}=$ The standard normal deviate, usually set at 1.96 which corresponds to $95 \%$ confidence level; $p=$ the proportion of target population estimated to have a particular characteristics which is $50 \%(0.5)$; $d=$ Permitted error $(5 \%$, if the confidence level is $95 \%) ; 0.05$ and $\mathrm{q}=1-\mathrm{p} ;(1-0.5=0.5)$

Therefore: $\mathrm{n}=\frac{(1.96 \times 1.96) \times 0.5 \times 0.5}{0.05 \times 0.05}$, hence $\mathrm{n}=384.16$

Since 384.16 was the least number of participants to be used for the study, attrition rate using percentage of return rate as $90 \%$ which gives 0.9 was calculated. Therefore, sample size $=384.16 \div 0.9=426.844$, which produced a final sample of 427 participants.

\subsection{Sampling Technique}

A multistage systematic sampling technique was used to select the youths from religious centers located in Ikeja, Lagos State at a fixed interval until desired sample was used. Religious centers were chosen as recruitment sites to ensure full representation of all in and out of school adolescents and youths. A total of 54 churches in the area were first identified after which a random sampling of the churches yielded 10 churches. The next step was to select the first church at random using hat method. Number 2 was selected. Therefore, all even number churches were selected for the study, which yielded 5 of the churches. The only mosque in the area was also used. A total of 427 participants were selected for the study which was derived by dividing 427 by 6 venues to give 71. Seventy-one participants were selected from each church 
and 72 from the mosque since it was the only known mosque in that area. This was done because the total number of youths in each church was unknown. A convenient sampling technique was then used to select the youths from the churches and mosque.

\subsection{Data Collection}

A closed and open-ended developed questionnaire was distributed to respondents with the aid of research assistants in the various centres. This was preceded by a pre-test. Cronbach's alpha reliability test was carried out and yielded a score of 0.717 . The questionnaire contained information on the demographic profile of respondents, general knowledge of A/YFRHS, Sources of knowledge about A/YFRHS, Services offered by A/YFRHS facilities and identification of locally available A/YFRHS. The 385 returned questionnaires were analysed using SPSS version 21. Univariate analysis was used to derive percentages and frequencies.

\subsection{Computation of Knowledge Scores}

Knowledge scores were computed by awarding one mark (1) to each correct answer and zero (0) for each incorrect answer. For each item, the responses 'yes' or 'no' were made available. The maximum obtainable score was 10 whereas the minimum was 0 . A composite knowledge was compiled together by adding together the individual knowledge scores. The scores were then classified into two categories by taking the mean of the highest and lowest scores. This was used to classify respondents into low and high levels of knowledge. Scores between 0-5.5 indicated low level of knowledge and 5.6-10 indicated high level of knowledge.

\section{Results}

Table 1. Respondents age, gender, religion and level of education $(n=385)$.

\begin{tabular}{lll}
\hline Variables & Frequency & Percentage \\
\hline Age & & \\
15-19 years & 109 & $29 \%$ \\
$20-24$ years & 265 & $69 \%$ \\
NA & 11 & $3 \%$ \\
Gender & & \\
Male & 162 & $42 \%$ \\
Female & 223 & $58 \%$ \\
Religion & & \\
Christianity & 344 & $89 \%$ \\
Muslim & 36 & $10 \%$ \\
NA & 5 & $1 \%$ \\
Level of Education & & \\
Primary & 0 & $0 \%$ \\
Secondary 101 & $26 \%$ & \\
Tertiary 249 & $65 \%$ & $7 \%$ \\
Others & 28 & $2 \%$ \\
NA & 7 & \\
\hline
\end{tabular}

Table 1 shows mean age of the participants was $20.47 \pm 2.081$. Sixty-nine percent of respondents were between 20 to 24 years of age. Most respondents were female, $223(58 \%)$, with more than half haven achieved tertiary education, $249(65 \%)$.
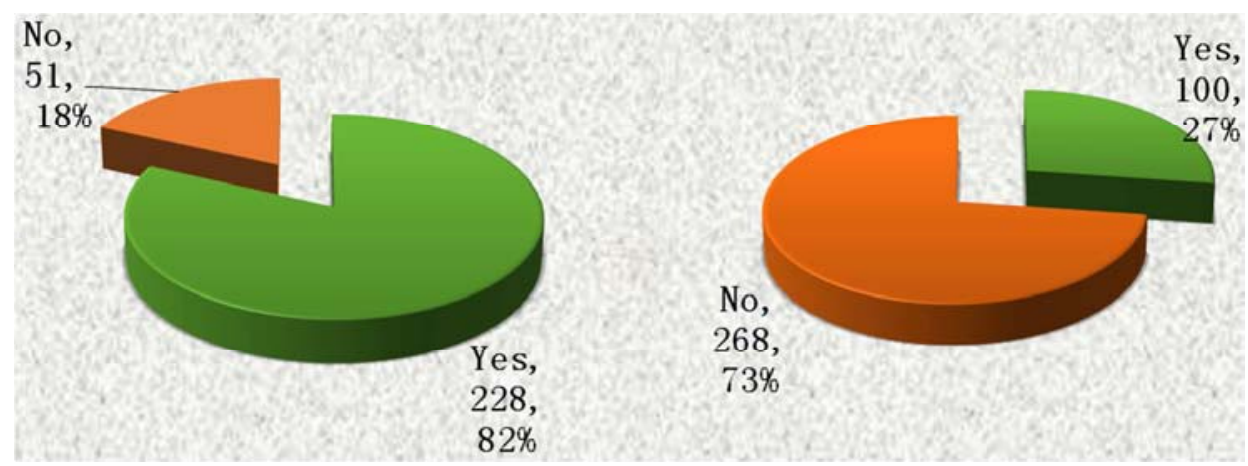

Figure 1. Respondents' knowledge about Adolescent/Youth Friendly Health Services.

${ }^{a}$ Respondents who know what adolescent/youth friendly services are

${ }^{\mathrm{b}}$ Respondents who know of any adolescent/youth friendly reproductive health facility

According to (Fig. 1) two-hundred and twenty eight of the respondents $(82 \%)$ knew what adolescent/youth friendly services are, while only $100(27 \%)$ knew of any adolescent/youth friendly reproductive health facility.

Table 2. Respondents' indication on the Adolescent/ Youth Friendly Reproductive Health Services they know of.

\begin{tabular}{llll}
\hline & Categories & Frequency & Percentage (\%) \\
\hline & Agodi at Ibadan/ARFH & 45 & 11.7 \\
& UNFPA & 17 & 4.4 \\
& PTD & 2 & 0.5 \\
Adolescent/youth friendly & LUTH & 5 & 1.3 \\
reproductive health facility & YASACH (NYSC) & 4 & 1.0 \\
known by respondents & Guardian and Counselling Centre & 3 & 0.8 \\
& Ikeja Medical Centre & 1 & 0.3 \\
& Hello Lagos & 29 & 7.5 \\
\hline
\end{tabular}


Adolescent/youth friendly reproductive health facility known and pointed out by respondents (TABLE 2) were Hello Lagos 29 (7.5\%), Association for Reproductive and Family Health 45 (11.7\%), United Nations Population's Fund (UNFPA) 17 (4.4\%) and others (16\%)

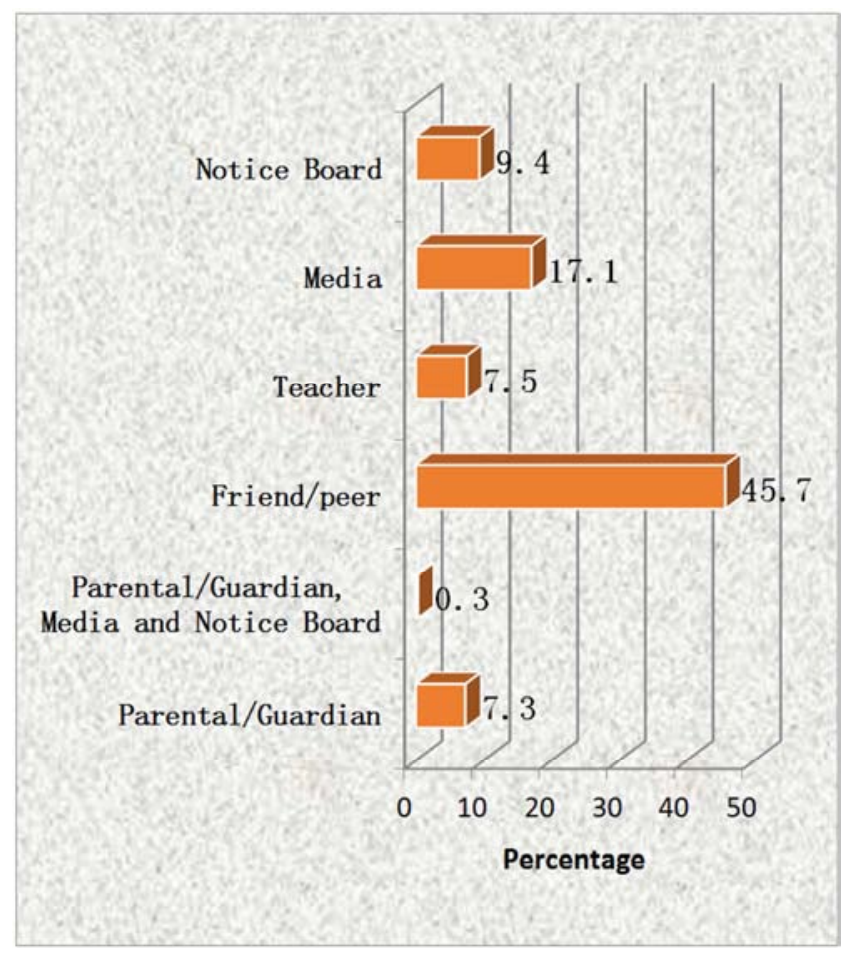

Figure 2. Source of information about adolescent/ youth friendly reproductive health services.

As shown in Fig 2, respondent's main source of information about adolescent/youth services were friends (45.7\%), followed by the media, (17.1\%) and parents (7.3\%).

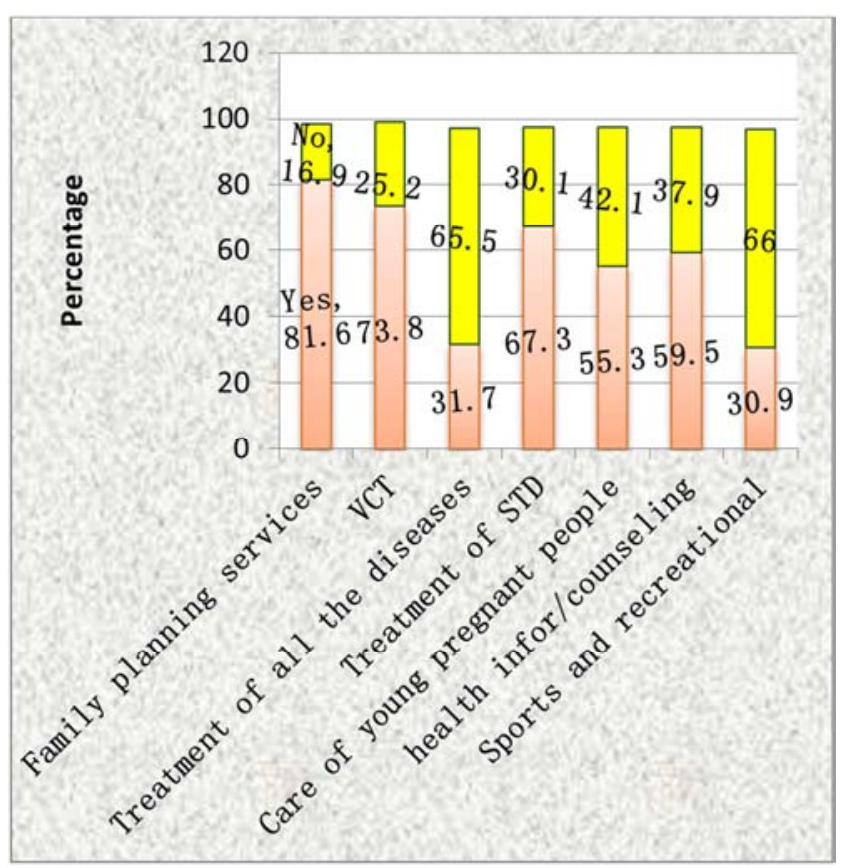

Figure 3. Services known by respondents that are offered in adolescentlyouth friendly facilities.

Regarding services offered by adolescent/youth reproductive health services as shown in Fig. 3 the following were mentioned; family planning services (contraceptives, condoms) (81.6\%), Voluntary Counselling and Testing (VCT) (73.8\%), treatment of sexually transmitted infections/diseases $(67.3 \%)$, care of young pregnant people $(55.3 \%)$ and others.

Table 3. Respondents' knowledge about adolescentlyouth services offered in the study area.

\begin{tabular}{llll}
\hline & Categories & Frequency & Percentage (\%) \\
\hline Do you know of any adolescent/youth friendly & Yes & 64 & 16.6 \\
reproductive health service provided in Lagos State & No & 306 & 79.5 \\
University Teaching Hospital (LASUTH), & Hello Lagos & 60 & 15.6 \\
& Guardian and Counselling centre & 2 & 0.5 \\
If yes, what is the name of the one you know? & Youth Empowerment initiatives, and others & 2 & 0.5 \\
\hline
\end{tabular}

According to table 3 majority (79.5 percent) of the respondents did not know of any adolescent/youth friendly reproductive health service provided in LASUTH (LASUTH is a foremost teaching hospital in the state), while 16.6 percent of the respondents knew of the existence of youth friendly reproductive health services in LASUTH. Only 15.6 percent of the respondents know Hello Lagos to be a youth friendly reproductive health service provided in LASUTH, and other facilities.

\section{Discussion}

Given that only $27 \%$ of the respondents knew of any adolescent/youth friendly services shows that knowledge remains a problem in the effort to address the unique sexual and reproductive health needs of the target population as also noted by [17] and [23]. Failure to recognize one of the few existing services which has been operating for up to 14 years also confirms very low awareness by the agency and hosting institution and a need to refocus on this unit. Poor knowledge and lack of awareness are main underlying factors that prevent adolescents from utilizing available sexual and reproductive health services [24].

Peer influence remains strong, as shown in this study where peers or friends were found to be the major source of information. This finding agrees with a study which found that 
youths who participated in peer to peer discussions were more likely to know about and utilize sexual and reproductive health services than those who did not participate [25]. That point was further justified by the fact that discussions of services with peers allowed youths to exchange information and experience to get awareness about services.

Poor knowledge about services in the study area was also an indicator of poor awareness in the area. Studies on local knowledge showed increased utilization of available YFRHS [17] among those who knew and registered for the services. This is in agreement with [12] who pointed out that "despite the satisfaction of youths with the available youth friendly sexual and reproductive services, service utilization was generally poor and this was partly attributable to the fact that majority of the youth had no knowledge of the existing facility based sexual and reproductive health service despite their existence in the study area". In addition study, most of the youths that utilized available A/YFRHS were knowledgeable of the services and consequences of nonutilization, so therefore more educated youths were found to utilize the available service more than non-educated youths as most of them were not aware of the consequence associated with the non-utilization of those available youth friendly services [8]. This indicates that awareness/knowledge of available services would motivate more youths to utilize the service.

Services mentioned by respondents were in line with services already known to be components of A/YFRHS as mentioned by $[15,26,27]$ which include counselling and testing, family planning, provision of sexual information, pregnancy testing and treatment of sexually transmitted infections (STI), provision of quality obstetric and antenatal care for all pregnant women and girls amongst others [27]. Respondents therefore had a good general knowledge of services.

\section{Conclusion}

This study was conducted in one of the local governments in the state and therefore does not provide a generalized presentation of the problem. It was observed that most of the youths knew what adolescent/youth friendly service were (where most of the respondents got their information from friends/peers) but majority of them did not know where to get these services from because they were not aware of the available adolescent/youth friendly facilities. Also, more than half of the respondents had no knowledge of the adolescent/youth friendly reproductive health service provided in LASUTH, a popular state health facility in the study area which has been in existence for about 14 years. The low level of knowledge indicates high level of unawareness and increased education is needed to assist youths in the area adequately utilize locally available services. For a change in the health status of these youths to occur there is need for great improvement in efforts to bring to their knowledge these services.

\section{References}

[1] Gaskia, J. 2014. "The condition of youth in Nigeria and the urgent imperative for political action."

http://saharareporters.com/2014/08/12/condition-youthnigeria-and-urgent-imperative-political-action-jaye-gaskia.

[2] Abebe, M., and W. Awoke. 2014. "Utilization of youth reproductive health services and associated factors among high school students in Bahir Dar, Amhara Regional State, Ethopia." Open Journal of Epidemiology 4 (2): 69-75. DOI: 10.4236/ojepi.2014.42012.

[3] Agampodi, S. B., T. C. Agampodi and U. K. Piyaseeli. 2008. "Adolescent perception of reproductive health care services in Sri Lanka." BMC Health Services Research 8 (98): 1-8. DOI: 10.1186/1472-6963-8-98.

[4] Lagos State Ministry of Health. (2016). Adolescent Sexuality and Reproductive Health (Hello Lagos) Retrieved from $\mathrm{http}: / /$ www.lsmoh.com/programme_info.php?programme_id=22.

[5] Kumar, R., S. Prinja, and P. V. Lakshmi. 2008. "Health seeking behaviour of adolescents: Comparative study of two service delivery models." Indian Journal of Pediatrics 75 (9): 895-899. DOI: 10.1007/s12098-008-0098-2.

[6] Roudi-Fahimi, F, and L. Ashford. 2008. "Sexual and Reproductive Health in the Middle East and North Africa: A Guide for reporters." Washington DC: Population Reference Bureau. http://www.prb.org/publications/mediaguides/2008/mediaguide.aspx.

[7] Omobuwa, O., E. O. Asekun-Olarinmoye, and F. O. Olajide. 2012. "Knowledge and perception of reproductive health services among in-school adolescents in Ile-Ife, Osun State, Nigeria." Journal of Medicine and Medical Sciences 3 (7), 2012, 481-488. http://www.interesjournals.org/fullarticles/knowledge-and-perception-of-reproductive-healthservices-among-in-school-adolescents-in-ile-ife-osun-statenigeria.pdf?view=inline.

[8] Feleke, S. A., D. N. Koye., A. F. Demssie, and Z. B. Mengesha. 2013. "Reproductive health service utilization and associated factors among adolescents (15-19 years old) in Gondar town, NorthWest Ethiopia." BMC Health Services Research, 13: 294. DOI: 10.1186/1472-6963-13-294.

[9] Mutati, Christine. M. 2012. "Adolescents Access to and Use of Reproductive Health Services in Ndola Urban, Masters thesis., University of Zambia.

[10] Carlisle, J. D. Shickle., M. Cork, and A. McDonagh. 2006. "Concerns over confidentiality may deter adolescents from consulting their doctors. A qualitative exploration." Journal of Medical Ethics 32 (3): 133-137. Doi: 10.1136/jme.2004.011262.

[11] Mbeba, R. M., M. S. Mkuye., G. E. Magembe., W. L. Yotham., A. O. Mellah, and S. B. Mkuwa. 2012. "Barriers to sexual reproductive health services and rights among young people in Mtwara district, Tanzania: a qualitative study." The Pan African Medical Journal 13 (1): 1-6. http://www.ncbi.nlm.nih.gov/pmc/articles/PMC3589247/.

[12] Depaah, J. M., S. C. Appiah., E. Badu., B. Obeng, and V. Ampiah. 2015. "Does facility based sexual and reproductive health services meet the needs of young persons? Views from section of Ghanaian youth." Advances in Sexual Medicine 5 (3), 61-71. DOI: 10.4236/asm.2015.53008 
[13] Breaken, D, and I. Rondinelli. 2012. "Sexual and reproductive health needs of young people: Matching needs with systems." International Journal of Gynecology and Obstetrics 119 (1): 2012, 60-63. DOI: 10.1016/j.ijgo.2012.03.019.

[14] McIntyre, P. 2012. "Adolescent friendly health services: an agenda for change, World Health Organisation." $\mathrm{WHO} / \mathrm{FCH} / \mathrm{CAH} / 02.14, \mathrm{UK}$.

[15] Akinyi, O. P. 2009. "Determinants of utilization of youth friendly reproductive health services among school and college youth in Thika West District, Kiambu County, Kenya.” Master's thesis., Kenyatta University.

[16] Fatusi, A. O. 2012. "National Standard and Minimum Service Package for Adolescent and Youth Friendly Health Services in Nigeria."

http://www.expandnet.net/PDFs/Nigeria_AHD\%20standards 2013.pdf

[17] Bedho T. K. 2014. "Assessment of utilization of youth friendly reproductive health services among college youth in Asela town, Oromia regional state, Ethiopia." masters thesis., Addis Ababa University.

[18] T. S. Mengistu, and A. T. Melku. 2013. "Sexual and reproductive health problems and service needs of university students in south east Ethiopia: Exploratory qualitative study." Science Journal of Public Health 1 (4): 184-188. http://dx.doi.org/10.4236/asm.2015.53008.

[19] Okereke, C. I. 2010. "Unmet Reproductive Health Needs and Health-Seeking Behaviour of Adolescents in Owerri Nigeria." African Journal of Reproductive Health 14 (1): 43-54. http://www.bioline.org.br/pdf?rh10004.

[20] Biddlecom, A. E., A. Muntbali., S. Singh, and V. Woog. 2007. "Adolescents' views of and preferences for sexual and reproductive health services in Burkina Faso, Ghana, Malawi and Uganda." African Journal of Reproductive Health 11 (3): 99-110.

http://www.ncbi.nlm.nih.gov/pmc/articles/PMC2367115/.
[21] Tegegn, A., M, Yazachew, and Y, Gelaw. 2013. "Reproductive health knowledge and attitude among adolescents." Ethiopian Journal for Health Development 22 (3): 143-151. http://ejhd.uib.no/ejhd-v22-

n3/243\%20Reproductive $\% 20$ health\%20knowledge $\% 20$ and $\% 2$ 0attitude\%20among\%20adolesc.pdf

[22] Lagos Bureau of Statistics. (2013). Lagos State Government: Digest of Statistics. Retrieved from http://www.lagosstate.gov.ng/2013_Digest\%20_of_Statistics.p $\mathrm{df}$

[23] Godia, P. M., J. M. Olenja., J. J. Hofman, and N. Broek. 2014. "Young people's perception of sexual and reproductive health services in Kenya." BMC Health Services Research 14: 172185. DOI: 10.1186/1472-6963-14-172.

[24] Oxfam. 2007. "Protocols for community-based youth-friendly health services for rural youth in the context of HIV and AIDS for EU/Oxfam Supported HIV/AIDS Prevention and Care Programme for Rural and Tribal Youth in India." IN/2007/ED/19, India, 3.

[25] Cherie, N. G Tura, and A. N, Teklehaymanot. 2015. Reproductive health needs and service utilization among youths." Journal of Public Health and Epidemiology 7 (4): 145-153. DOI: 10.5897/JPHE2014.0700.

[26] International Planned Parenthood Federation. (2007). A guide for developing policies on sexual and reproductive health and rights of young people in Europe. Brussels. $\mathrm{http} / / /$ www.ippfen.org/resources/sexual-and-reproductivehealth-right-young-people-europe-guide-developing-policies

[27] United Nations Population Fund. 2014. Adolescent Sexual and Reproductive Health. Retrieved from http://www.unfpa.org/resources/adolescent-sexual-andreproductive-health\#sthash.rDgxZozj.dpuf 